\title{
Regeneration and Flowering in Vitro of 'Burpless Hybrid' Cucumber Cultured from Excised Seed
}

\author{
W. Msikita ${ }^{1}$, R.M. Skirvin ${ }^{2}$ J.A. Juvik ${ }^{3}$, W.E. Splittstoesser ${ }^{2}$, and \\ N. Ali $^{1}$ \\ Department of Horticulture, University of Illinois, Urbana, IL 61801
}

Additional index words. cotyledons, growth regulators, Cucumis, tissue culture

Abstract. Seeds of 'Burpless Hybrid' cucumber (Cucumis sativus L.) were separated from their seedcoats and excised into pieces comprising an embryonic axis and two cotyledons. The seed pieces were disinfested and explanted on modified Murashige and Skoog medium with 16 combinations of BAP (2.0, 3.0, 4.0, $\left.5.0 \mathrm{mg} \cdot \mathrm{liter}^{-1}\right)$ and NAA $\left(0.0,0.1,0.2,0.3 \mathrm{mg} \cdot\right.$ liter $\left.^{-1}\right)$. On all media, embryonic axes germinated and grew into whole plants within 4 weeks, but did not flower. Cotyledons developed adventitious shoots and male flowers on most media. A few female flowers developed. The best shoot regeneration and the most female flowers were observed on medium with $2.0 \mathrm{mg}$ BAP and $0.3 \mathrm{mg}$ NAA/liter. One of the female flowers was pollinated in vitro and it developed a small fruit with viable seed.

In vitro regeneration of cucumbers has been a subject of considerable interest, and various explants have been used to develop calli and regenerate plants. Explants that have regenerated shoots have included seedling cotyledons (Kim and Jang, 1984; Kim et al., 1988; Sekioka and Tanaka, 1981), hypocotyl segments (Rajasekaran et al., 1983), leaf blades and petioles (Wehner and Loey, 1981), and axillary buds (Handley and Chambliss, 1979).

A tissue culture system that would enable successful regeneration from mature, excised dry seed pieces would offer a means to rapidly multiply plants when only a limited number of seed is available. Cade et al. (1987) reported shoot regeneration from cotyledons of Cucumis sativus L. after subculturing and/or transferring to another type of medium and maintaining the explants in the dark. Lange and Juvik (1986) also reported regeneration from mature seed cotyledons of several Cucurbita species. Msikita et al. (1988) recently reported preliminary observations regarding shoot regeneration from several cucumber cultivars and lines, and observed that cucumber shoot regeneration and subsequent flowering varied among genotypes and type of explant. In this paper, we report shoot regeneration and flowering of the cucumber cultivar Burpless Hybrid at

Received for publication 9 Dec. 1988. This research was supported in part by the Univ. of Illinois Agricultural Experiment Station (Hatch 650323), the Swedish International Development Authority (SIDA), and the Zambian Ministry of Agriculture and Water Development (MAWD). We thank Hassan Abu-Qaoud for the statistical analysis. The cost of publishing this paper was defrayed in part by the payment of page charges. Under postal regulations, this paper therefore must be hereby marked advertisement solely to indicate this fact.

'Graduate Student.

${ }^{2}$ Professor.

${ }^{3}$ Associate Professor. various concentrations of BAP and NAA.

Cotyledons and embryonic axis explants. Seed of 'Burpless Hybrid' cucumber (provided by Sakata Seed Co., Japan) were separated from their seedcoats and cut into pieces consisting of an embryonic axis and two cotyledons. The pieces were disinfested (10 $\mathrm{min}$ ) in $10 \%(\mathrm{v} / \mathrm{v})$ Clorox, to which $40 \mathrm{mg}$ of Alconox powder had been added as a surfactant, and then rinsed five times (30 see/ rinse) with sterile water. The pieces from a single seed were maintained as a clone and aseptically transferred to $25 \times 150-\mathrm{mm}$ culture tubes (one seed piece per tube) containing $10 \mathrm{ml}$ of modified Murashige and Skoog (MS) (1962) high salt medium supplemented with 16 combinations of BAP and NAA (Table 1). Before autoclaving $\left(1.06 \mathrm{~kg} \cdot \mathrm{cm}^{-2}\right.$ pressure, $15 \mathrm{~min}$ ), $10 \mathrm{ml}$ of Staba (1969) vitamins were added. The $\mathrm{pH}$ of the media was adjusted to 5.7 , and 7\% (w/v) Difco Bacto-agar was added. Explants were placed into the media vertically, with the basal cut end $\approx 1$ to $2 \mathrm{~mm}$ beneath the surface of the medium.

The experimental treatment consisted of 25 seeds divided into two cotyledons and one embryonic axis each $(75$ explants $\times 16$ media). Cotyledon explants were grown for 8 weeks under 16-hr daylength in a culture room. Light $\left(40 \mu \mathrm{mol} \cdot \mathrm{s}^{-1} \cdot \mathrm{m}^{-2}\right)$ was provided by cool-white fluorescent lamps. The temperature was maintained at $25 \pm 2 \mathrm{C}$. The experiment was repeated three times and was designed to be a $4 \times 4$ factorial, with 25 pairs of cotyledons as replications for four levels each of BAP and NAA. Data were analyzed using the General Linear Model procedure of SAS (1982). The cultures were examined weekly for their growth, shoot regeneration, and flowering.

To assess the type of regeneration, some of the regenerating cotyledons were embedded in paraffin and later $10-\mu$ pieces were sectioned on a microtome, mounted on glass slides, and stained in safranin and fast green as described by Johansen (1940).

Transfer of in vitro-derived plants to soil. Some of the shoots obtained in this study were transplanted to small plastic pots $(0.15$ liters) containing a 1 sterilized peat $: 1$ perlite $: 1$ soil mixture (by volume) and placed in the culture room under the conditions described earlier. After 5 to 7 days, plantlets were transferred to a greenhouse.

In vitro pollination. At anthesis, some of the female flowers that developed in vitro were pollinated from male, greenhouse-grown cucumber flowers. To reduce potential contamination of the tissue culture medium during pollination, the greenhouse-grown male flowers were bagged 1 day before anthesis. On the following day, the flowers were removed and pollen was carefully extracted onto a sterile petri dish with a sterile scapel. Using a small brush (sterilized by autoclaving), pollen was carefully transferred onto the stigmas of two female cucumber flowers in vitro.

To verify pollen viability, pollen from greenhouse- and in vitro-derived male flowers was stained with acetocarmine and examined under a microscope.

After 3 days of culturing, explants began to expand and turn green. Subsequent growth was different for each explant type.

Embryonic axes. The embryonic axes germinated, a radicle grew from the axis, and it thickened with callus. Callused roots later branched. Callus formation was particularly pronounced on explants cultured on medium with $2 \mathrm{mg}$ BAP and $0.2 \mathrm{mg}$ NAA/liter. Some of this callus persisted until the plants were removed to soil.

Some cultures developed 2 to 3 axillary shoots. Within 3 to 4 weeks of culturing, the shoots were large enough to transplant to soil. No flowering was observed in vitro.

Cotyledons: shoot regeneration. Within 2 weeks, cotyledons expanded to more than 10 times their original size (Fig. 1, top). By the 3rd week of culturing, callus formed in the region of the cut surface. Some callus rapidly developed organized structures (Fig. 1, top). Some of these structures became plantlets within 6 to 8 weeks of explanting. Some plantlets produced flowers (Fig. 1, bottom). Shoots arose adventitiously from the callus (Fig. 2). Shoots had no preformed root system, suggesting they arose via organogenesis.

Table 1. Average effect of BAP and NAA on flower differentiation from cucumber cotyledons cultured in vitro for 8 weeks $(n=25)$.

\begin{tabular}{|c|c|c|c|c|}
\hline \multirow{2}{*}{$\begin{array}{c}\text { BAP } \\
\left(\mathrm{mg} \cdot \mathrm{liter^{-1 }}\right)\end{array}$} & \multicolumn{4}{|c|}{ NAA (mg liter $\left.{ }^{-1}\right)$} \\
\hline & 0.0 & 0 & 0.2 & 0.3 \\
\hline
\end{tabular}

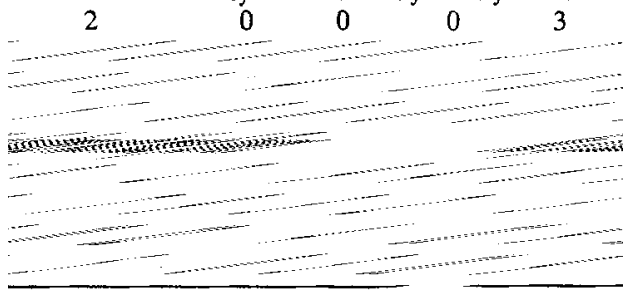




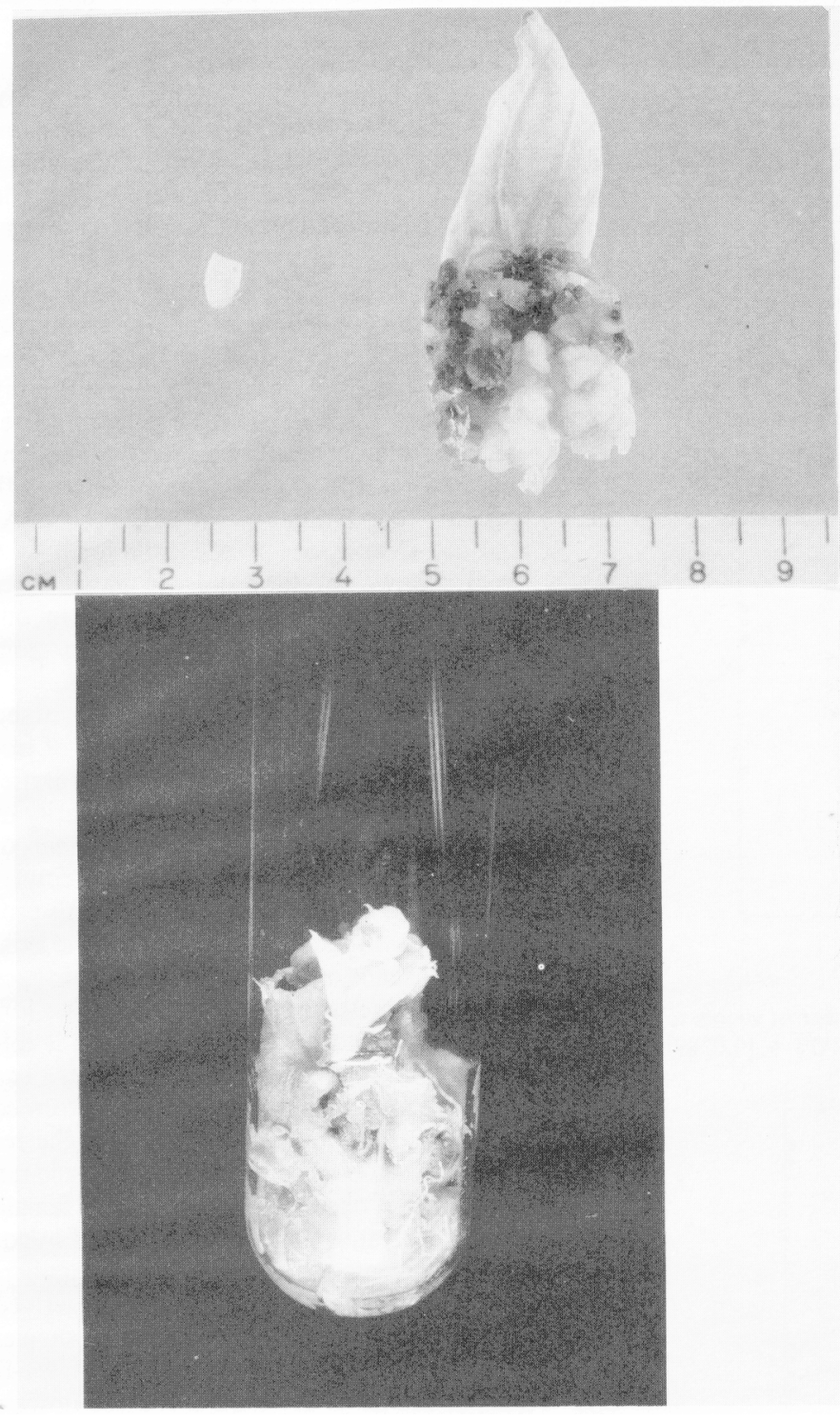

Fig. 1. In vitro development of adventitious shoots and flowers of 'Burpless Hybrid' cucumber. Adventitious shoot development (top right) from an embryonic axis-free cotyledon (top left); a male flower that has developed on a regencrated shoot (tube diameter $=2.5 \mathrm{~cm})($ bottom); the in vitro development of a cucumber fruit from a pollinated female flower that developed in vitro (tube diameter $=2.5 \mathrm{~cm})($ far right).

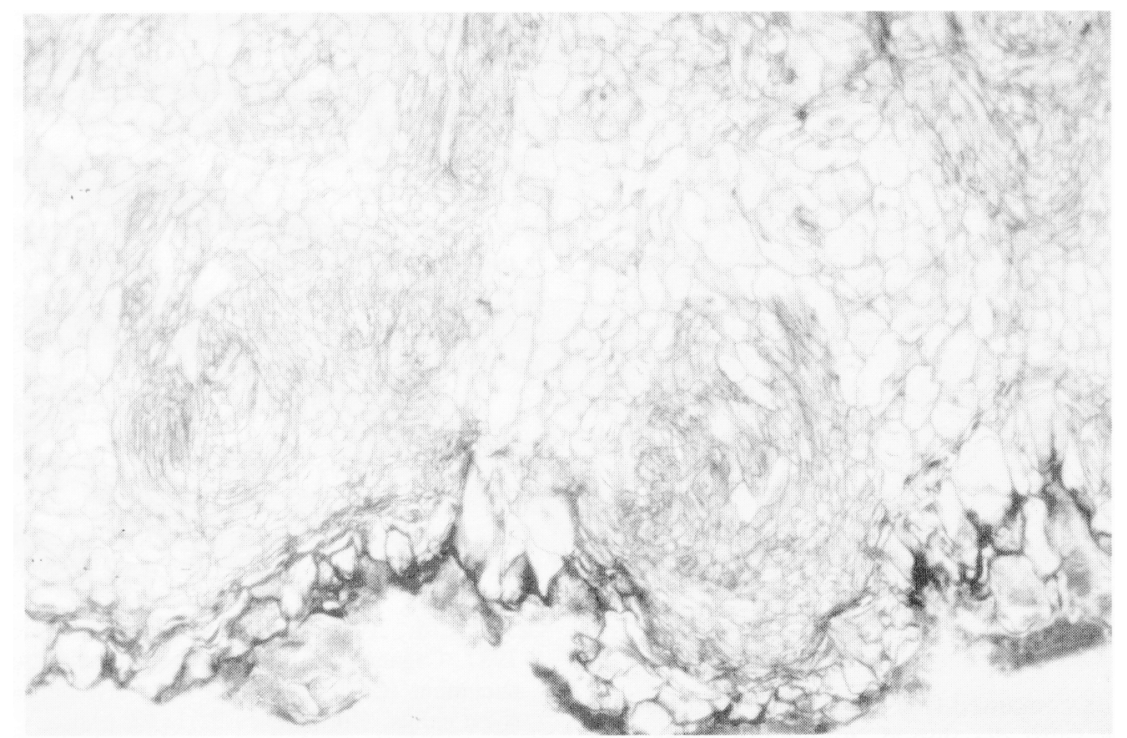

Fig. 2. An early stage of adventitious shoot formation from callus on a cotyledon of 'Burpless Hybrid' cucumber.
Shoots were obtained at each level of BAP and NAA. There was no significant interaction between NAA and BAP for shoot regeneration. The best shoot regeneration was on medium supplemented with $2 \mathrm{mg}$ BAP/ liter. Shoot regeneration was significantly reduced by increasing BAP concentration from 2 to $5 \mathrm{mg} \cdot \operatorname{liter}^{-1}$ (Fig. 3). The highest average shoot regeneration due to NAA was observed between 0.2 and $0.3 \mathrm{mg} \cdot$ liter $^{-1}$ (Fig. 4); beyond $0.3 \mathrm{mg} \cdot$ liter $^{-1}$ average shoot number declined.

Flowering. By the 7th week of culture, some of the shoots developing on cotyledons began to flower. Male flowers (Fig. 1, bottom) were observed on all media, except that supplemented with $5 \mathrm{mg}$ BAP/liter alone. The most male flowers were produced at $4 \mathrm{mg}$ BAP/liter with various combinations of NAA (Table 1). Female flowers were observed only on media supplemented with either $2 \mathrm{mg}$ BAP and $0.3 \mathrm{mg} \mathrm{NAA} /$ liter or $4 \mathrm{mg} \mathrm{BAP/liter}$ alone. On the latter medium, female flowers were very poorly developed. 


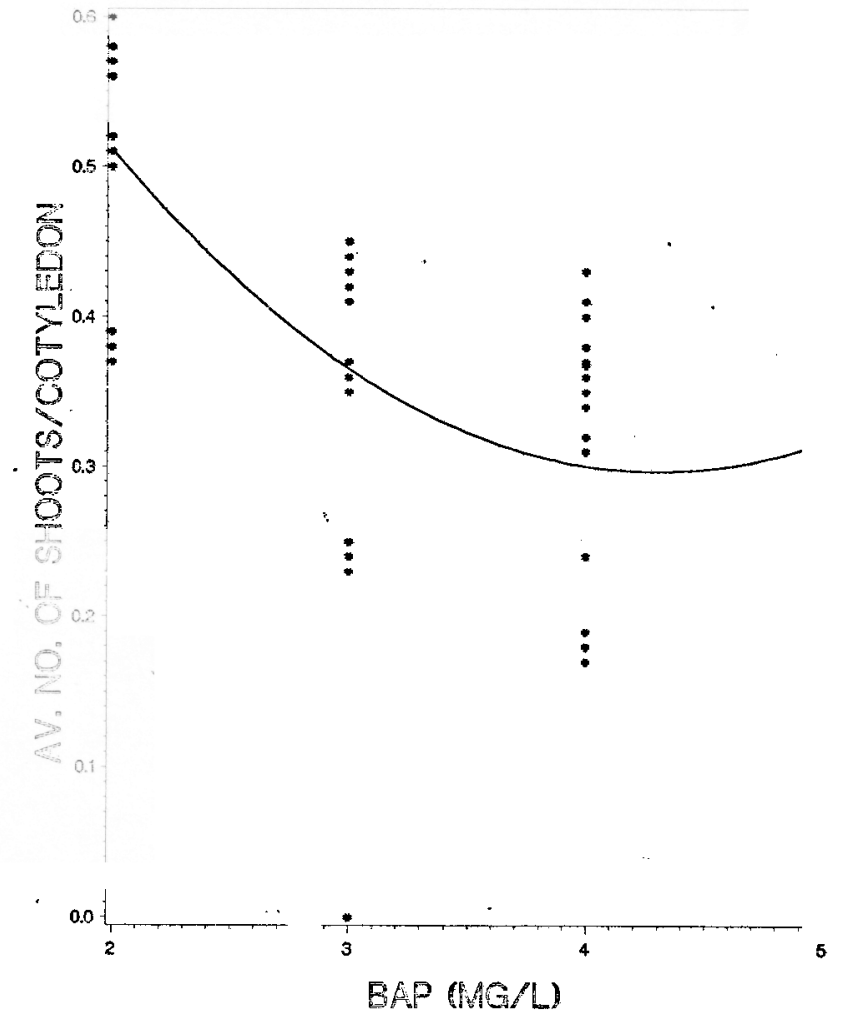

Fig. 3. Average effect of BAP over four levels of NAA on the average number of shoots regenerated from 'Burpless Hybrid' cucumber cotyledons. \{Shoots $=0.892-(0.329 \mathrm{XBAP})+\left[0.0389 \mathrm{X}\left(\mathrm{BAP}^{2}\right)\right]$, $\left.r^{2}=0.856\right\}$

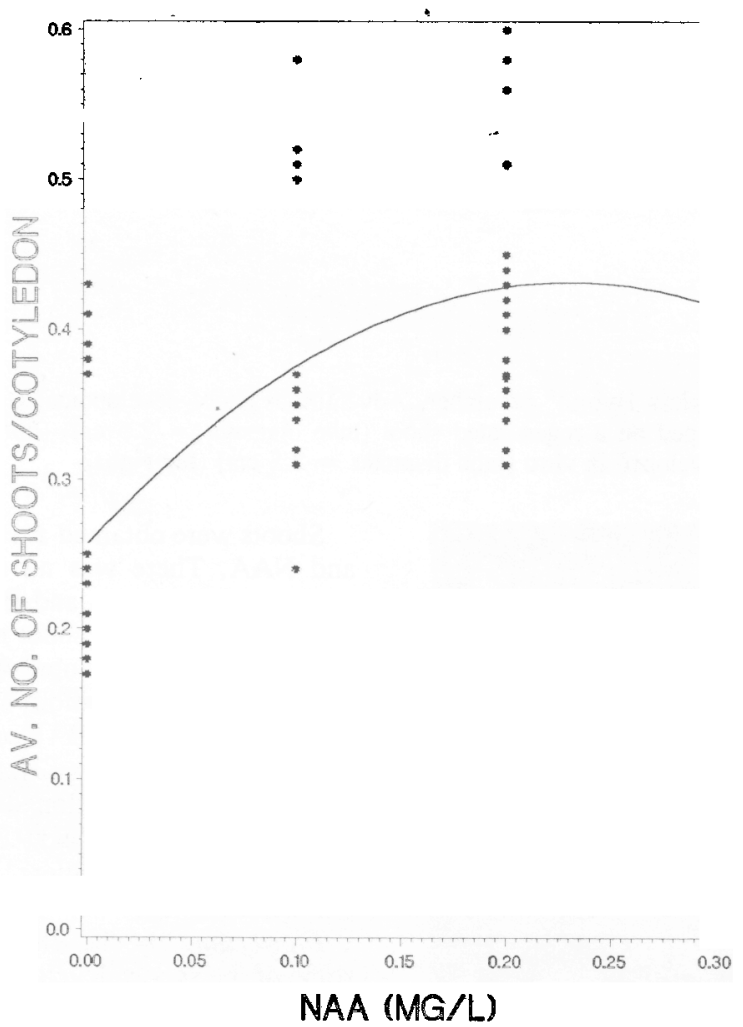

Fig. 4. Average effect of NAA over four levels of BAP on the average number of shoots regenerated from 'Burpless Hybrid' cucumber cotyledons. \{Shoots $=0.892+(1.5 \mathrm{XNAA})-\left[3.036 \mathrm{X}\left(\mathrm{NAA}^{2}\right)\right]$, $\left.r^{2}=0.856\right\}$

In vitro pollination. Each of the female flowers pollinated in vitro developed a small cucumber fruit (Fig. 1, far right) that were harvested from the culture tube at maturity, i.e., when they turned yellow. One of the fruits contained two seeds. One of the seeds was fully developed, while the other was empty. The second fruit contained no seed. The embryo was removed from the viable seed and recultured; it germinated after 5 days and grew into a plant.

The viability of the pollen from in vitroderived male flowers was verified by staining with acetocarmine. Most of the pollen grains ( $>95 \%$ ) stained red, were round, and similar in appearance to those from a greenhouse plant.

In this study, the best shoot regeneration (50\%) from cotyledons was obtained on media supplemented with either $2 \mathrm{mg}$ BAP and $0.3 \mathrm{mg}$ NAA/liter or $4 \mathrm{mg}$ BAP and $0.3 \mathrm{mg}$ NAA/liter. Cade et al. (1987) reported regeneration from cucumber seed cotyledons cultured on MS media supplemented with various combinations of BAP, NAA, and 2,4-D and kept in the dark for 4 to 6 weeks; however, they did not indicate regeneration frequency or flowering. In our study, shoots were regenerated directly from dried seed cotyledons in 6 to 8 weeks.

The consistent formation of organized structures proximal to the cut surface of isolated cotyledons was also noted in our earlier report (Msikita et al., 1988). The polarity of shoot regeneration suggests a gradient of growth-promoting factors within the cotyledons and/or the translocation of growth-p romoting substances toward the embryonic axis.

The absence of flowers on embryonic axes in vitro suggests the stimulus for flower formation on preformed embryonic axes is different from that of adventitious shoots. The presence of the embryonic axis (a preformed shoot) also may impart juvenility to the regenerated shoot (Scorza, 1982). Rajasekaran et al. (1983) observed both male and female flower formation in vitro on cultured hypocotyl segments of 'Superpickle' cucumber. Flowers were observed on hypocotyl-derived shoots after 20 weeks on MS medium supplemented with BA (0.5 or $1.0 \mu \mathrm{M})$ and 2,4-D $(1.5$ or $5.0 \mu \mathrm{M})$. The ability of these flowers to set seed or serve as a pollen source was not reported. In our study, the ability of the female flowers to set fruit and viable seed, as well as the viability of the pollen from in vitro-derived male flowers, was demonstrated.

The protocol developed in this study offers an in vitro method to regenerate cucumbers from dried seed cotyledons and embryonic axes. In addition, this system may be useful to 1) obtain many plantlets from a single seed, 2) study the control of flowering in vitro, and 3 ) serve as a possible alternative to conventional methods of cucumber breeding, e.g., the production of somaclonal variants (Larkin and Scowcroft, 1981).

\section{Literature Cited}

Bottino, P.J. 1981. Vegetable crops, p. 141-164. In: B.V. Conger (ed.). Cloning agricultural plants via in vitro techniques. CRC Press. Boca Raton, Fla.

Cade, R.M., T.C. Wehner, and F.A. Blazich 1987. Organogenesis and embryogenesis from cucumber (Cucumis sativus L.) cotyledon-derived callus. HortScience 22:1130. (Abstr.)

Garcia-Sogo, M., I. Granelli, and B. Garcia-Sogo 1986. Plant regeneration from explant-derived calli of Cucumis anguria L. var. longipes. $\mathrm{Cu}$ curb. Genet. Coop. 9:108-109. 
Handley, L.W. and O.L. Chambliss. 1979. In vitro propagation of Cucumis sativus L. HortScience 14:22-23.

Johansen, D.A. 1940. Plant microtechnique, p. 145-154. McGraw-Hill, New York.

Kim, S.G., J.R. Chang, H.C. Cha, and K.W. Lee. 1988. Callus growth and plant regeneration in diverse cultivars of cucumber (Cucumis sativus L.). Plant Cell Tissue \& Organ Cult. 12:67-74.

Kim, S.G. and J.R. Jang. 1984. Regeneration of plants from callus tissue of cucumber (Cucumis sativus L.) seedling cotyledons. Plant Physiol. 75:15. (Abstr.)

Lange, N.E. and J.A. Juvik. 1986. Organogenesis from explants of mature seed cotyledons of 20 accessions from the genera Cucurbita, Cucumis and Citrullus. HortScience 21:687. (Abstr.)
Larkin, P.J. and W.R. Scowcroft. 1981. Somaclonal variation-A new source of variation from cell cultures for plant improvement. Theor. Applied Genet. 60:197-214.

Msikita, W., R.M. Skirvin, J.A. Juvik, and W.E. Splittstoesser. 1988. In vitro regeneration and flowering of cucumber cultivars and lines cultured from excised seed. Cucurb. Genet. Coop. 11:5-7.

Murashige, T. and F. Skoog. 1962. A revised medium for rapid growth and bioassays with tobacco tissue cultures. Physiol. Plant. 15:474497.

Rajasekaran, K., M.G. Mullins, and Y. Nair. 1983. Flower formation in vitro by hypocotyl explants of cucumber (Cucumis sativus L.). Ann. Bot. 52:417-420.
SAS Institute, Inc. 1982. SAS user's guide. SAS Inst., Cary, N,C.

Scorza, R. 1982. In vitro flowering. p. 106-127. In: J. Janick (ed.). Horticultural reviews. vol. 4. AVI Publishing Co., Westport, Conn.

Sekioka, A.J. and J.S. Tanaka. 1981. Differentiation in callus cultures of cucumber (Cucumis sativus L.). HortScience 16:451. (Abstr.)

Staba, J.E. 1969. Plant tissue culture as a technique for the phytochemist, p. 75-106. In: M.K. Seikel and V.C. Runeckles (eds.). Recent advances in photochemistry. vol. 2. AppletonCentury Crofts, N.Y.

Wehner, T.C. and R.D. Loey. 1981. In vitro adventitious shoot and root formation of cultivars and lines of Cucumis sativus L. HortScience 16:759-760. 